\title{
EL ROL DE GÉNERO EN LOS VIDEOJUEGOS
}

Resumen: La educación para la igualdad requiere de la implicación de todas y cada una de las agencias que participan de este proceso. En este trabajo hemos querido conocer en qué medida los videojuegos más vendidos y utilizados por la población infantil y juvenil transmiten contenidos que contribuyen a su educación para la igualdad o, por el contrario, la dificultan. Para ello hemos analizado el contenido de los diez videojuegos más jugados por menores y adolescente, atendiendo a los valores y disvalores que transmiten, centrando nuestra atención en la representación de modelos de mujer y roles de género. Por último, hemos tratado de establecer una serie de conclusiones y orientaciones pedagógicas, dejando abierta la posibilidad de desarrollar futuras investigaciones en esta línea.

Palabras Clave: Educación para la igualdad, género, familia, infancia, adolescencia

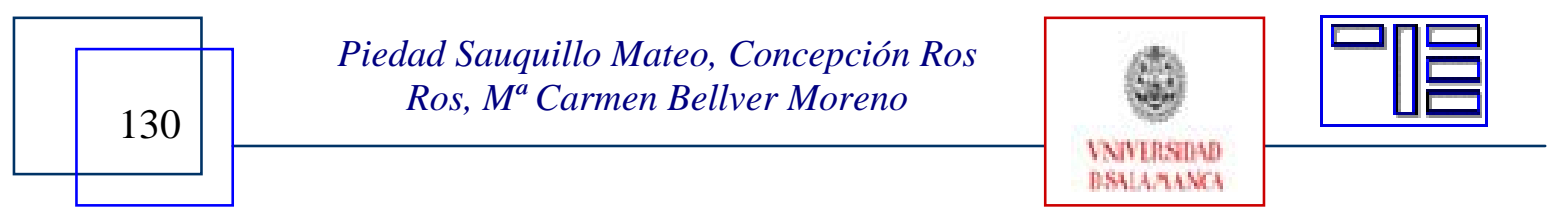




\section{THE ROLE OF GENDER IN VIDEOGAMES}

Abstract: Education for equality requires the involvement of each and every one of the agencies involved in this process. In this work we wanted to know if the most played video games by children and adolescents transmit content that contribute to their education for equality or not. We have analysed the content of the ten most played games by children and adolescents, according to the values and disvalues transmited, focusing our attention on the model representation of women and gender roles. Lastly, we have tried to establish some conclusions and teach guidelines, leaving open the possibility of developing future research along these lines.

Keywords: Education for equality, gender, family, childhood, adolescence

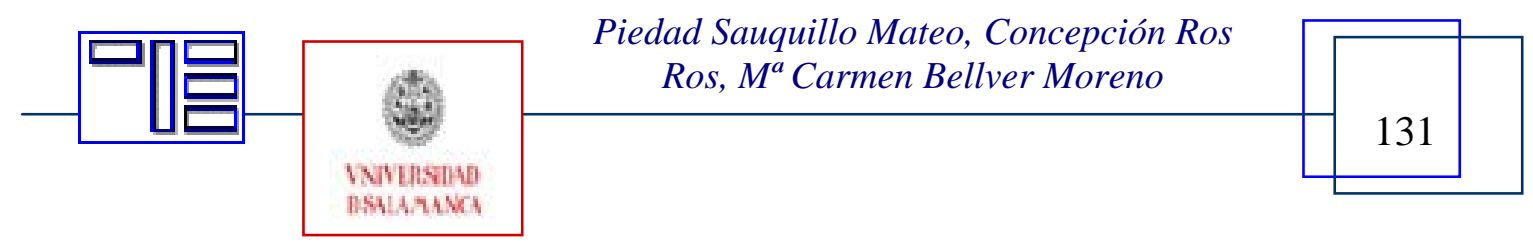




\section{LE RÔLE DES FEMMES DANS LES JEUX VIDÉO}

Sommaire : L'éducation pour l'égalité exige la participation de tous et de chacun des organismes impliqués dans ce processus. Dans ce travail nous voulions savoir combien de jeux vidéo vendus et utilisés transmettre le contenu qui contribue à leur éducation à l'égalité ou, au contraire, entravent l'éducation. Nous avons analysé le contenu des dix plus de parties jouées par les enfants et les adolescents, selon les valeurs et la transmission, concentrant notre attention sur le modèle de représentation des femmes et des rôles des sexes. Nous avons essayé de mettre en place une série de conclusions et de l'enseignement des lignes directrices, en laissant ouverte la possibilité de développer la recherche future dans ce sens.

Mots clefs: éducation pour l'égalité, sexe, famille, enfance, adolescence

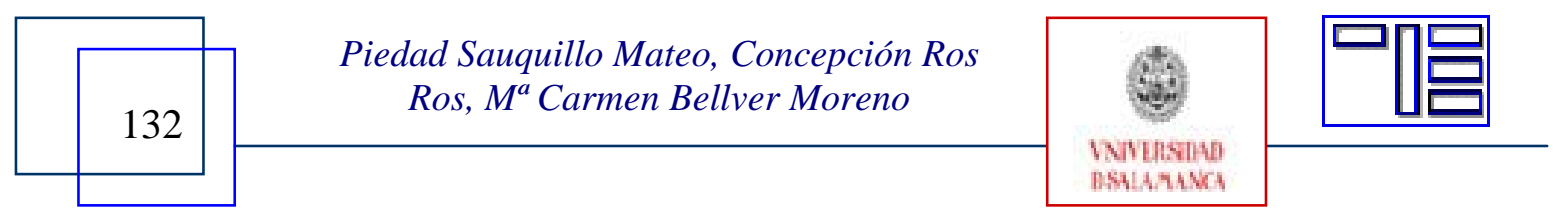




\title{
EL ROL DE GÉNERO EN LOS VIDEOJUEGOS
}

\author{
Piedad Sauquillo Mateo \\ piedad.sahuquillo@uv.es \\ Concepción Ros Ros \\ concepcion.ros@uv.es \\ $\mathrm{M}^{\mathrm{a}}$ Carmen Bellver Moreno \\ M.Carmen.Bellver@uv.es \\ Universitat de València
}

\section{INTRODUCCIÓN}

Son muchas y muy diversas las definiciones que se han ido dando del término "medios de comunicación social o medios de comunicación de masas”. En palabras de Cabero y Loscertales (1995:103), los medios de comunicación se entienden como "aquellos sistemas mediáticos de información unidireccional, que de forma individual o en interacción, transmiten mensajes. Estos sistemas mediáticos responden a una serie de características básicas que los diferencia de otros, como por ejemplo los medios audiovisuales y las nuevas tecnologías de la información y la comunicación”.

Sin duda, el papel de los videojuegos es destacable no sólo por su actual facilidad en el acceso sino sobre todo, porque ejerce efectos sustantivos en la formación de los ciudadanos, en la configuración y transmisión de valores y actitudes. Es por ello que, hemos de ser conscientes que junto a los beneficios aportados, también encierran ciertos peligros, efectos perniciosos que desde el mundo educativo hemos de considerar e intentar compensar.

Desde nuestra perspectiva, planteamos la importancia de los videojuegos como agencia socializadora, principalmente, en dos sentidos: como medio que presenta diferentes posibilidades educativas, ya que se puede convertir en una escuela complementaria al aprendizaje del niño, cumpliendo así una función socializadora positiva; pero también como medio peligroso, pues viene caracterizado sobre todo por una comunicación unidireccional que fomenta la pasividad en los telespectadores, ofrece una visión panorámica, no experiencial, de la realidad y es contraria al diálogo constructivo, necesario para el buen desarrollo de niños y adolescentes. La creatividad, el desarrollo

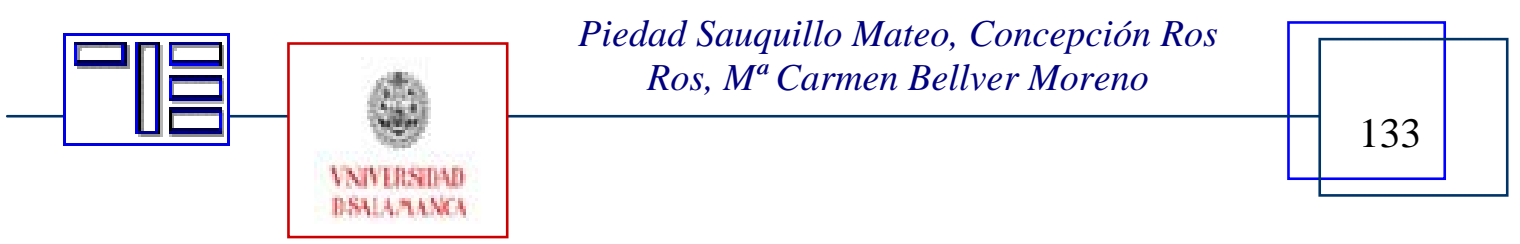


de la imaginación, el esfuerzo, la responsabilidad, etc. se pueden ver afectados negativamente.

Del mismo modo, se ha venido observando a través de diferentes investigaciones que "los medios tienen un impacto particularmente poderoso cuando presentan conocimientos que van más allá de la experiencia directa del espectador” (Tuchman, 1988:619), ya que es en ese momento cuando el espectador ha de entrar a formar parte activa, a introducirse en el mundo mediático, a imaginar situaciones todavía no vividas.

\section{2.- QUÉ SON Y QUÉ NOS OFRECEN LOS VIDEOJUEGOS}

Para poder definir qué entendemos por videojuegos, en el marco de los medios de comunicación, recogemos aquí las aportaciones de Marqués (2000) al respecto. Este autor considera que son todo tipo de juegos electrónicos interactivos, con independencia de su soporte (ROM interno, cartucho, disco magnético u óptico, on-line) y plataforma tecnológica (máquina de bolsillo, videoconsola conectable a la televisión, máquina recreativa, microordenador, vídeo interactivo, red telemática). Junto a esta definición, la Real Academia de la Lengua Española los define como dispositivo electrónico que permite, mediante mandos apropiados, simular juegos en las pantallas de un televisor o de un ordenador.

Tomando como referencia las aportaciones de Rodríguez (2002), podemos afirmar que las características que definen a los videojuegos son las que a continuación se señalan:

- Libre: El sujeto accede a él de forma voluntaria y lo termina cuando quiere.

- Improductiva: La finalidad del juego está en si mismo. Es el propio juego y no el producto final lo que interesa.

- Placentera: Está unida a la risa, el humor, la diversión, la satisfacción y el entretenimiento.

- Ficticia: Es algo diferente a la vida corriente, tiene un poder de evasión temporal.

- Limitada en el tiempo y en el espacio: Tiene un lugar de realización, un principio y un fin.

- Normalizada: Regulada por reglas y normas específicas, aceptadas y/o consensuadas por todos. Si no se cumplen el juego se acaba. Se aceptan y rechazan valores.

Cabe señalar aquí que los videojuegos, al igual que ocurre con el resto de medios de comunicación, son reflejo de la sociedad en que nos ha tocado vivir y a la que desde nuestra propia esfera personal y social contribuimos. En este sentido, tal y como señalan Gómez del Castillo (2001) y Díez (2004), hemos de permanecer atentos a determinados

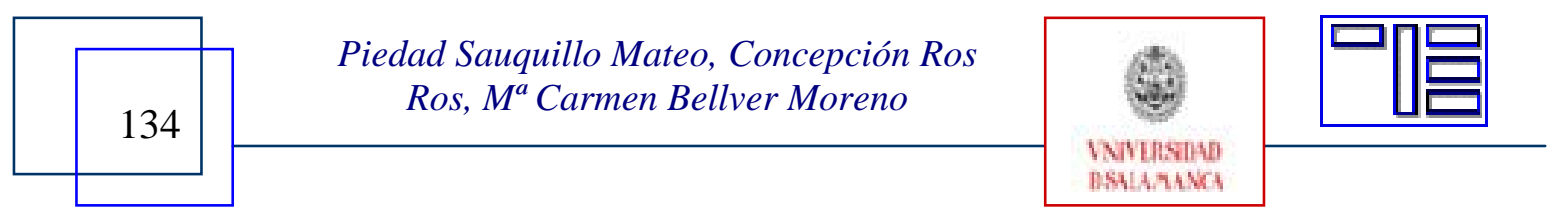


valores y disvalores que pueden (y de hecho así ocurre) influir en la educación de los más jóvenes. A saber:

- El sexismo: pues, como tratamos de analizar en nuestro trabajo, habitualmente reproducen los roles de una cultura machista tradicional.

- Estereotipos físicos: en los videojuegos podemos descubrir que, tanto hombres como mujeres, son en su mayoría jóvenes, esbeltos, guapos y blancos. Con frecuencia, presentan cuerpos de proporciones poco reales (ropa ajustada, pechos de grandes dimensiones, grandes escotes, transparencias, faldas cortas, etc.)

- Fantasías eróticas de dominio/sumisión: Aunque no siempre sucede así, en algunos videojuegos aparecen estas actitudes.

- Competitividad como forma frecuente de relación, por encima de la cooperación, colaboración, ayuda al otro, etc.

- El fin justifica los medios: El deseo de alcanzar la victoria o conseguir el objetivo prevalece por encima de cómo conseguirlo.

- Visión maniquea de la realidad: La dinámica seguida en los videojuegos nos ofrece un mundo dividido en mejores y peores, ganadores y perdedores, buenos y malos, y el objetivo es aprender a "machacar" a los demás para sobrevivir pero, sobre todo, para ser el mejor. Esto es más frecuente en los juegos de acción.

- Menosprecio a los débiles: Es poco frecuente la aparición de personas que tengan ciertas dificultades o deficiencias, personas mayores, etc.

- La violencia y las agresiones son demasiado frecuentes: De hecho, en algunos videojuegos, el único objetivo es matar, torturar, disparar... a mujeres, iraquíes, vietnamitas, palestinos, guerrillas latinoamericanas, nazis...etc, potenciando así la animadversión hacia cualquier colectivo que no sea el del protagonista-ganador del videojuego.

- Algunos autores defienden que la violencia en los videojuegos es más perjudicial que la de la TV o el cine, ya que en estos medios el espectador mantiene una actitud pasiva, mientras que en los videojuegos el sujeto asume una actitud protagonista en esas situaciones de agresividad extrema cada vez mayor y más realista. Sin embargo, otros defienden que sirve como forma de catarsis y que contribuyen a disminuir la violencia en la vida real. Desde nuestra perspectiva, el verdadero problema radica en que se conviva con la violencia de modo habitual, con naturalidad, pudiendo llegar a ser insensible a ella.

- Racismo: Raramente encontramos negros, árabes, gitanos..., en los videojuegos y, cuando esto sucede, suelen aparecer como "los malos". (aunque muchos fabricantes son orientales)

- Pensamiento único: los videojuegos transmiten a menudo la imposibilidad de pensar de otra manera distinta a la del poder dominador actual. Habitualmente se entiende en este tipo de juegos que tanto el poder como el

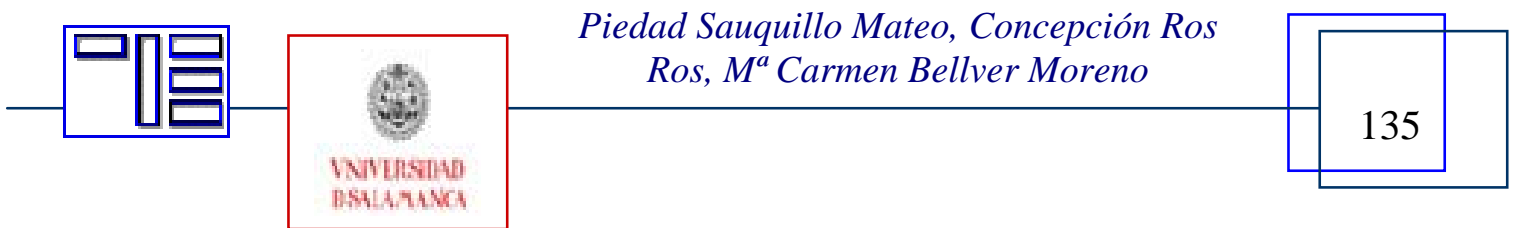




\begin{tabular}{|c|c|c|}
\hline \multirow[t]{2}{*}{ 凹ص } & \multicolumn{2}{|c|}{$\begin{array}{l}\text { Revista Electrónica Teoría de la Educación. } \\
\text { Educación y Cultura en la Sociedad de la Información. }\end{array}$} \\
\hline & http://www.usal.es/teoriaeducaci & Vol. 9. $N^{\circ}$ 3. Noviembre 2008 \\
\hline
\end{tabular}

dinero son los motores de la historia y que el modelo social deseable es el de la clase media-alta.

- Impulsividad: Con frecuencia se favorece la actuación del jugador sin previa reflexión, sin pensar en las consecuencias de lo que hace, sobre todo por el factor tiempo que obliga a precipitar las acciones.

\subsection{Los videojuegos como agente de socialización temprana.}

Podemos afirmar que hoy vivimos en una sociedad bien diferenciada de aquella con la que contábamos hace algún tiempo, cuando los niños eran niños durante mucho más tiempo y la adolescencia y adultez eran mucho más tardías. Sin embargo, ello no supone adoptar una postura negativa ante nuestra realidad. Antes bien, conlleva una invitación al conocimiento de las circunstancias en que les ha tocado vivir, de modo que podamos contribuir a su optimización.

Así, en este apartado tratamos de abordar una cuestión que viene planteándose desde principios de los años 90 (Postman, 1990) relativa a la progresiva desaparición de la infancia como tal, a la excesivamente pronta incorporación de los niños y niñas a la vida adulta, a la pérdida de etapas de gran calidad educativa y lúdica. Y es precisamente en este contexto donde los medios de comunicación (en nuestro caso concreto los videojuegos) desarrollan una labor protagonista en la transmisión de modelos y estilos de vida para la infancia. Así, ofrecen de forma constante modelos de vida y de comportamiento antes de que ocurra la auténtica experiencia. De este modo, los niños encuentran en los medios, lecciones sobre la vida y las conectan con su propia experiencia, pudiendo pesar mucho esto en la conformación de las expectativas y aspiraciones de los propios niños (DeFleur, 1964; Tuchman et al., 1978).

Postman (1982) postula que los medios van desvelando esos secretos, sobre todo, en lo que respecta a la sexualidad, la violencia y la competencia de los adultos para dirigir el mundo. A esto cabe añadir la constante presencia del papel claramente diferenciado que desempeñan mujer y hombre, es decir, la transmisión de roles de género que, con total naturalidad visionan los jugadores desde edades bien tempranas.

En un mismo orden de cosas, Garbarino et al. (1992) inciden en cómo los menores aprenden modelos agresivos a través de los medios desde edades bien tempranas, ven cómo los personajes (cada vez con mayores visos de realidad) logran lo que desean haciendo uso de la violencia, de modo que ésta parece no sólo funcional sino también la clave del éxito en la vida adulta.

Pérez Alonso-Geta (2005), postula el concepto de "reducción de la infancia” al plantear que hoy vemos como muchos niños pierden la oportunidad de gozar jugando a muchas cosas, de escuchar historias, de descubrir por ellos mismo aspectos de la vida a un ritmo preciso y no precipitado. En buena medida los videojuegos contribuyen a que esto sea

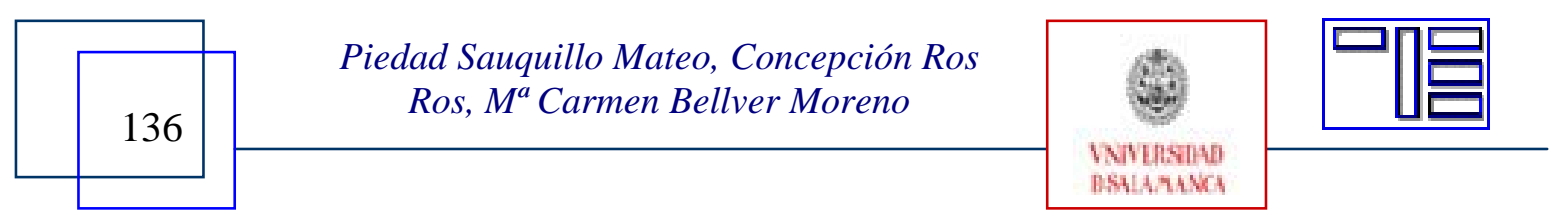


así, pues ocupan gran parte de su tiempo, sustituyendo incluso el contacto humano, el diálogo y el disfrute de la vida en común.

En este sentido, Rosengren (1992) también vincula la reducción actual de la etapa infantil a la influencia de los medios de comunicación. Este autor plantea que se constituyen en agentes de socialización de gran importancia, contribuyendo a crear la percepción de los niños de la realidad cultural en la que viven. A través de los medios no sólo se les transmiten contenidos puramente informativos, sino también (y sobre todo) valores, actitudes, normas sociales, etc. que están a la base de la cultura en que niños y adolescentes se encuentran inmersos, generando así un efecto socializador en la población estudiada. En palabras de De Bofarull (2005:65) "la inocencia de un niño que debe descubrir la vida y su realidad de un modo paulatino, en consonancia con su desarrollo psicoevolutivo, con su capacidad de entender y elaborar las cosas que surgen ante él, ha quedado tocada”.

En este sentido, por lo que respecta a los videojuegos y a su potencial influencia en la vida de los sectores más jóvenes de la población, podemos afirmar que en general suelen mostrar y hacer uso de la competitividad, de alcanzar el objetivo de ser siempre el primero; junto a esto, lo verdaderamente preocupante es que se persiga ser el mejor en la violencia, en el sexismo y el racismo, en el consumismo y en las formas aburguesadas de vida. Es obvio que los videojuegos cuyo objetivo radica en la consecución de acciones solidarias y altruistas por parte del jugador son minoritarios respecto a los ya comentados. Al respecto podemos citar algún ejemplo: Food Force (videojuego creado desde el Programa Mundial de Alimentos de la ONU para menores entre 8 y 13 años que invita a realizar misiones humanitarias en una isla ficticia); Guerra Espiritual o Éxodo: Viaje a la Tierra Prometida (tratan de compaginar las cuestiones bíblicas, la acción trepidante y valores como la verdad y la honestidad.

\subsection{El tratamiento del rol de género en los videojuegos}

Los videojuegos utilizan como recursos la imagen, el texto, la música y las características específicas del propio medio en un contexto general de valores y actitudes acuñados en sociedad, por lo cual, frecuentemente, reproduce estereotipos y prejuicios que no responden a una sociedad en transformación pero que todavía persisten en el imaginario colectivo. Así ocurre en el caso del tratamiento que se da con demasiada frecuencia al rol de la figura femenina y masculina, en los mensajes televisivos, o en los propios videojuegos. Los estudios realizados en torno a esta cuestión revelan que la transmisión de valores sexistas y del papel que se les han asignado tradicionalmente no es exclusiva de los videojuegos, sino que están presentes en muchos medios (Levis 1997, Estallo 1997, Gros 1998, Díez 2004).Resulta preocupante que pese a todos los protocolos desarrollados, todas las normativas redactadas (LEY ORGÁNICA 3/2007, de 22 de marzo, para la igualdad efectiva de mujeres y hombres, BOE n. 71 de 23/3/2007), todas las propuestas de mejora

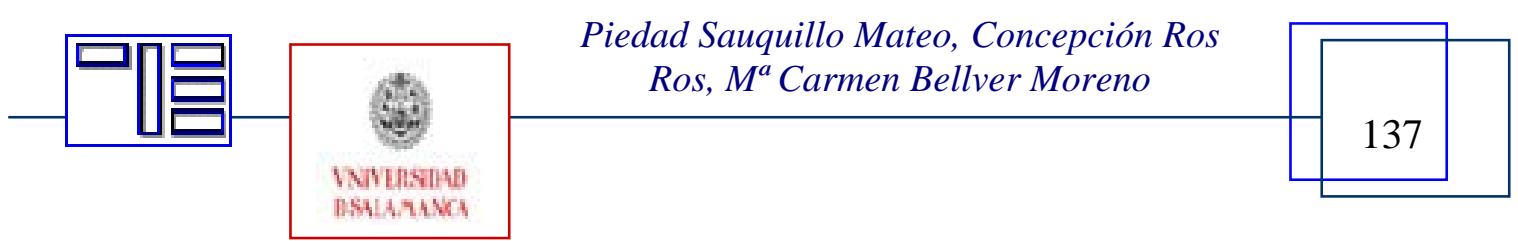


planteadas, la realidad en los medios de comunicación siga siendo otra bien diferente a la deseable. Así, entre otros foros de discusión, destacamos aquí la exigencia planteada tanto en el II Foro Galego sobre Mulleres e medios de comunicación (2000) como en la IV y V Conferencia Mundial sobre la Mujer (1995-2005) para erradicar la proyección de imágenes negativas y degradantes de la mujer en los medios de comunicación, diferentes asociaciones como la AAUW o Committe on Women in Computing es un claro exponente de que no se está dando una situación igualitaria en materia de sexos, sobre todo porque los medios no ofrecen una imagen equilibrada de los diversos estilos de vida de las mujeres y de su aportación a la sociedad en un mundo en evolución. Otro punto a tener en cuenta es la denominada "brecha digital", la AAUW (Tuya, 2000), solicita continuamente la ayuda de educadores, padres y profesores para potenciar las habilidades tecnológicas de las niñas, como destacan diversos autores (Gargallo, 2008) aun estamos distantes de conseguir que las TIC sean un recurso para la igualdad de género.

En este sentido, niños y niñas y adolescentes se encuentran en la pequeña pantalla (TV, los videojuegos...) con multitud de modelos con los que parcial o totalmente tienden a identificarse (Pérez Alonso-Geta, 1994) modelos que tienen una incidencia específica en los estereotipos sexistas y modos de conducta de las niñas y niños y adolescentes por pertenecer a segmentos de población acríticos por naturaleza:

Así pues, más allá de su valor como diversión o evasión, los medios de comunicación (y concretamente los videojuegos), cumplen una función socializadora de la que las personas usuarias no suelen ser conscientes. Es por ello que suelen ser más eficaces desde el punto de vista socializador por cuanto actúan de manera inadvertida (Ferrés, 1998).

En pleno siglo XXI en el que los logros sociales apuntan hacia la igualdad en todos los ámbitos (social, familiar, laboral, etc.), nos encontramos con que una de las principales vías que existen para perpetuar la desigualdad, como son los estereotipos de género, forman parte de la cotidianeidad de niños, niñas y jóvenes.

Así, los menores continúan experimentando e incorporando toda una serie de pautas de conducta y de pensamiento que contribuyen al mantenimiento de las diferencias, fortaleciendo del principio básico de la desigualdad. Además, la escuela no consigue avanzar hacia un escenario coeducativo que consiga combatir los elementos de discriminación para explotar todo el potencial de las generaciones futuras, erradicando de raíz buena parte de los elementos discriminatorios que suponen un lastre para el desarrollo de las personas y de la humanidad en su conjunto.

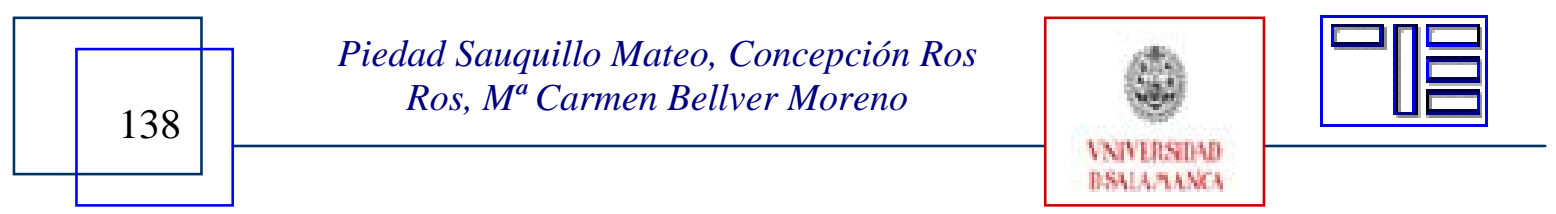




\section{3.- MÉTODO}

La realización de este trabajo ha requerido de una metodología que nos permita conocer y profundizar en los contenidos que se transmiten mediante el uso de los videojuegos analizados, sobre todo, atendiendo al rol desempeñado por la mujer.

Conlleva, consecuentemente, en su realización los siguientes pasos:

\section{Determinación de tópicos (contenidos a estudiar).}

Se trata de analizar los valores, actitudes, pautas de acción y roles desempeñados a partir de la muestra de videojuegos estudiada. Así, a través de los contenidos de los videojuegos, los individuos pueden elaborar, descubrir y cambiar sus creencias ya que los contenidos de los mismos transmiten valores tanto a través de lo que se dice como a través de los modelos que ofrecen.

Con todos estos tópicos se construyeron y concretaron las categorías de análisis contenido a emplear.

\section{Fases del análisis de contenido.}

Realizado un primer análisis de los videojuegos más vendidos para identificar los valores, disvalores, actitudes, pautas de acción, etc. propuestos en ellos se decidió utilizar la dinámica conocida como “Texto-Análisis-Interpretación” en nuestro caso adoptando la forma “juego-análisis-interpretación” cuyas fases secuenciales son las siguientes:

\section{- Elección de los videojuegos}

En una primera aproximación, realizamos un estudio de los videojuegos más vendidos a lo largo de la historia, partiendo de los datos ofrecidos por el diario británico Independent (citado en "El Universal, 2007). Tras el análisis de estos 20 videojuegos más vendidos, se seleccionaron y analizaron 10 videojuegos tomando como criterios los que siguen:

- Son los más vendidos y, por ende, llegan a más cantidad de población

- En todos aparece alguna referencia y se representa un rol concreto del género femenino y masculino

- Son videojuegos destinados a la población objeto de nuestro estudio (infancia y adolescencia, etapa fundamental en cuanto a la formación de la personalidad, etc.)

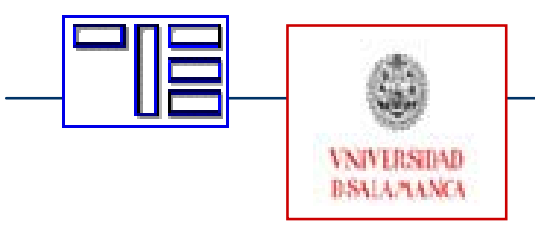

Piedad Sauquillo Mateo, Concepción Ros Ros, $M^{a}$ Carmen Bellver Moreno 


\section{- $\quad$ Definición del Universo.}

El Universo objeto del estudio quedó definido por un total de 10 videojuegos. El listado obtenido aparece en la siguiente tabla.

\begin{tabular}{|c|}
\multicolumn{1}{c|}{ Videojuegos analizados } \\
\hline VIDEOJUEGOS \\
\hline MARIO BROS \\
\hline POKEMON \\
\hline FINAL FANTASY \\
\hline THE SIMS \\
\hline THE LEGEND OF ZELDA \\
\hline GRAND THEFT AUTO \\
\hline TOMB RAIDER \\
\hline MORTAL KOMBAT \\
\hline STREET FIGHTER \\
\hline RESIDENT EVIL \\
\hline
\end{tabular}

- Unidades de análisis

Las unidades de análisis son portadoras de información y sirven de base para el análisis. En nuestro trabajo la unidad de análisis quedó definida como las secuencias o "episodios interactivos" que se dan entre los personajes que aparecen en los videojuegos. Analizándose a través de unidades de registro diferenciadas en función de los distintos tipos de contenidos transmitidos. Con el fin de lograr mayor objetividad y fiabilidad se transcribieron literalmente todos los episodios interactivos y se registraron para su posterior análisis. Para ello fue necesario visionar primero y jugar después con todos los videojuegos objeto de nuestro estudio.

En la transcripción de los Episodios interactivos y la codificación de contenidos se recogió la información que a continuación se detalla:

- Datos de Identificación del videojuego (nombre del videojuego, fabricante, público a que va dirigido, edad recomendada, soporte informático requerido, etc)

- Acciones relevantes (relaciones interpersonales, diálogo, misiones a ejecutar, etc.)

- Contenidos (los contenidos registrados hacen referencia a valores y disvalores, actitudes y comportamientos en los que se ponen en marcha las distintas conductas, valores, actitudes, etc. )

- $\quad$ Categorización. Construcción de las categorías utilizadas para el análisis de los videojuegos

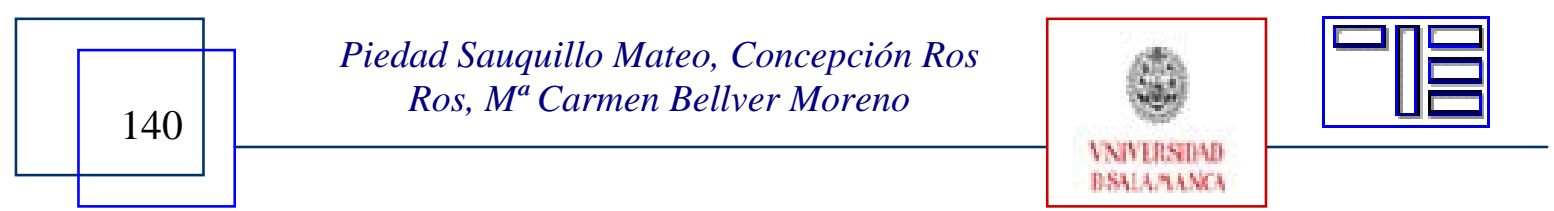


La categorización tiene como objetivo efectuar una clasificación de las unidades de registro. Las categorías deben ser exhaustivas y mutuamente excluyentes y han de responder a los siguientes requisitos:

Exclusión mutua. La misma categoría no puede clasificarse en varias casillas del mismo tipo.

Homogeneidad. La organización de las categorías debe realizarse en función de un mismo principio de clasificación.

Pertinencia. Deben estar adaptadas al material de análisis seleccionado.

Objetividad y fiabilidad. Sometidos a varios análisis los mismos episodios interactivos, deben ser codificados de la misma manera.

\section{$\underline{\text { Categorías }}$}

Las categorías resultantes utilizadas para el análisis de los videojuegos son:

1- Protagonistas del videojuego: se pretende analizar si el videojuego presenta protagonistas masculinos o femeninos.

2.- Relación que se establece entre los protagonistas masculinos y femeninos del videojuego en función de los roles asignados y la naturaleza-contenidos de las interacciones

3. Tratamiento de la figura de la mujer en el videojuego

4. Valores/Disvalores socioculturales que se trasmiten a través del contexto/acción en que se desarrolla el videojuego

5. Análisis de los valores que trasmite el rol femenino.

Determinación del sistema de cuantificación. Elaboración del instrumento de medida: $\underline{\text { Rejillas }}$

Partiendo de los anteriores supuestos se elaboró el correspondiente instrumento de medida (rejilla de registro) que tras sucesivos pilotajes quedó definitivamente cerrada. Para la elaboración de la rejilla final se tuvo en cuenta tanto la frecuencia de aparición como el nivel de concentración de las distintas categorías.

\section{- $\quad$ Tratamiento estadístico de los datos}

Las técnicas utilizadas para el procesamiento de los datos obtenidos han consistido, básicamente, en el análisis de frecuencias y porcentajes, a nivel de estadísticos simples.

\section{4.- ANÁLISIS DE RESULTADOS:}

A continuación analizaremos los datos obtenidos tras la realización de nuestro estudio. Estos datos se muestran, de modo general, en la siguiente tabla.

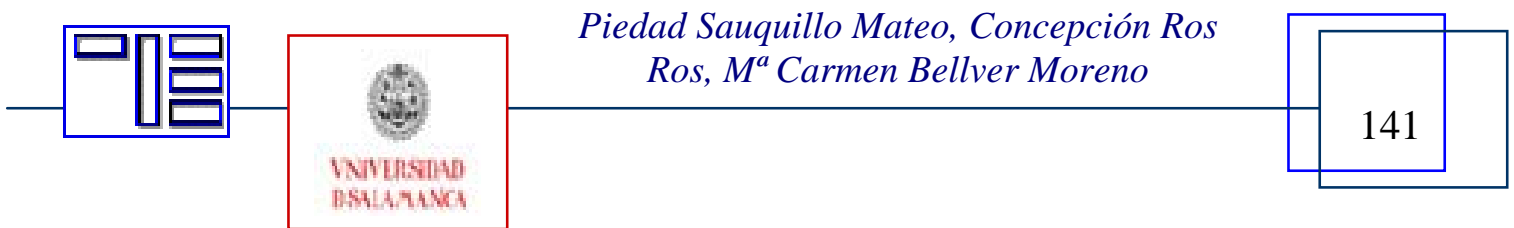




\section{Tabla $n^{\circ} 1$}

\begin{tabular}{|l|l|l|l|l|l|}
\hline $\begin{array}{l}\text { VIDEOJUEG } \\
\text { OS } \\
\text { ANALIZADO } \\
\text { S }\end{array}$ & \multicolumn{1}{|c|}{ Protagonistas } & $\begin{array}{c}\text { Relación } \\
\text { hombre/muj } \\
\text { er }\end{array}$ & \multicolumn{1}{|c|}{ Figura mujer } & $\begin{array}{c}\text { Valores/Dis } \\
\text { valores } \\
\text { Sociocultur } \\
\text { ales }\end{array}$ & $\begin{array}{l}\text { Valores } \\
\text { representa } \\
\text { dos por la } \\
\text { figura } \\
\text { femenina }\end{array}$ \\
\hline $\begin{array}{l}\text { RESIDENT } \\
\text { EVIL }\end{array}$ & $\begin{array}{l}\text { Residente vil 3 mujer } \\
\text { En otra versión se } \\
\text { puede elegir }\end{array}$ & Dominación & Sexi/erótica & Bélicos & $\begin{array}{l}\text { Agresiva } \\
\text { masculina }\end{array}$ \\
\hline $\begin{array}{l}\text { THE } \\
\text { LEGEND OF } \\
\text { ZELDA }\end{array}$ & Masculino & $\begin{array}{l}\text { Dominación } \\
\text { y } \\
\text { dependencia } \\
\text { masculina }\end{array}$ & $\begin{array}{l}\text { Pasiva } \\
\text { (de rol masculino) }\end{array}$ & Bélicos & $\begin{array}{l}\text { Maternal } \\
\text { (pedir } \\
\text { ayuda) }\end{array}$ \\
\hline $\begin{array}{l}\text { STREET } \\
\text { FIGHTER }\end{array}$ & $\begin{array}{l}\text { 18 protagonistas } \\
5 \text { mujeres }\end{array}$ & Dominación & $\begin{array}{l}\text { Agresivas } \\
\text { (luchadoras) }\end{array}$ & Bélicos & agresiva \\
\hline $\begin{array}{l}\text { MORTAL } \\
\text { KOMBAT }\end{array}$ & $\begin{array}{l}\text { Masculinos , algunas } \\
\text { mujeres masculinizadas }\end{array}$ & Dominación & Sexi/erótica & Bélicos & agresiva \\
\hline $\begin{array}{l}\text { SUPER } \\
\text { MARIO } \\
\text { BROS }\end{array}$ & $\begin{array}{l}\text { Masculinos. } 7 \text { hombres } \\
\text { y mujer }\end{array}$ & $\begin{array}{l}\text { Héroe/Domi } \\
\text { nación }\end{array}$ & Pasiva (Barbie) & Bélicos & $\begin{array}{l}\text { Maternal } \\
\text { Barbie }\end{array}$ \\
\hline $\begin{array}{l}\text { FINAL } \\
\text { FANTASY }\end{array}$ & $\begin{array}{l}\text { Masculino } \\
\text { 4aballeros }\end{array}$ & $\begin{array}{l}\text { Mujer, } \\
\text { secundario }\end{array}$ & Pasiva secundario & Bélicos & $\begin{array}{l}\text { Pasiva } \\
\text { rescatada }\end{array}$ \\
\hline $\begin{array}{l}\text { TOMB } \\
\text { RAIDER }\end{array}$ & $\begin{array}{l}\text { Femenino } \\
\text { (masculinizada) }\end{array}$ & Dominación & Sexi/agresiva & Bélicos & $\begin{array}{l}\text { Agresivos } \\
\text { masculinos }\end{array}$ \\
\hline $\begin{array}{l}\text { GRAND } \\
\text { THEFT } \\
\text { AUTO }\end{array}$ & Masculino & Dominación & $\begin{array}{l}\text { Pasiva/objeto sexual } \\
\text { Prostitutas }\end{array}$ & Bélicos & $\begin{array}{l}\text { Masculina } \\
\text { sumisión }\end{array}$ \\
\hline POKEMON & Masculino & Dominación & Pasivas(cariñosas) & Bélicos & $\begin{array}{l}\text { Maternal } \\
\text { animada }\end{array}$ \\
\hline THE SIMS & $\begin{array}{l}\text { Masculino } \\
\text { Familia }\end{array}$ & Dominación & $\begin{array}{l}\text { Pasiva } \\
\text { (rol establecido) }\end{array}$ & $\begin{array}{l}\text { Sociales } \\
\text { tradicionales }\end{array}$ & $\begin{array}{l}\text { Valores } \\
\text { sociales } \\
\text { predetermi } \\
\text { nados }\end{array}$ \\
\hline
\end{tabular}

(Fuente: Plantilla de análisis que incluye todos los elementos de análisis descritos y utilizados en nuestro estudio)

A partir de los resultados que se muestran en la anterior tabla $\mathrm{n}^{\circ} 1$ analizaremos con detenimiento cada de las categorías utilizadas en nuestro estudio así como los porcentajes obtenidos en cada una de ellas.

Categoría 1: Protagonistas del videojuego

\begin{tabular}{|l|l|l|l|}
\hline \multicolumn{1}{c|}{} & \multicolumn{3}{c|}{ Tabla $^{\circ} 2$} \\
\cline { 2 - 4 } & $\begin{array}{l}\text { PREDOMINIO } \\
\text { PROTAGONISTAS } \\
\text { MASCULINOS }\end{array}$ & $\begin{array}{l}\text { PREDOMINIO } \\
\text { PROTAGONISTAS } \\
\text { FEMENINOS }\end{array}$ & $\begin{array}{l}\text { PROPORCIÓN } \\
\text { EQUITATIVA }\end{array}$ \\
\hline $\begin{array}{l}\text { PROTAGONISTAS } \\
\text { DEL VIDEOJUEGO }\end{array}$ & $70 \%$ & $30 \%$ & - \\
\hline
\end{tabular}

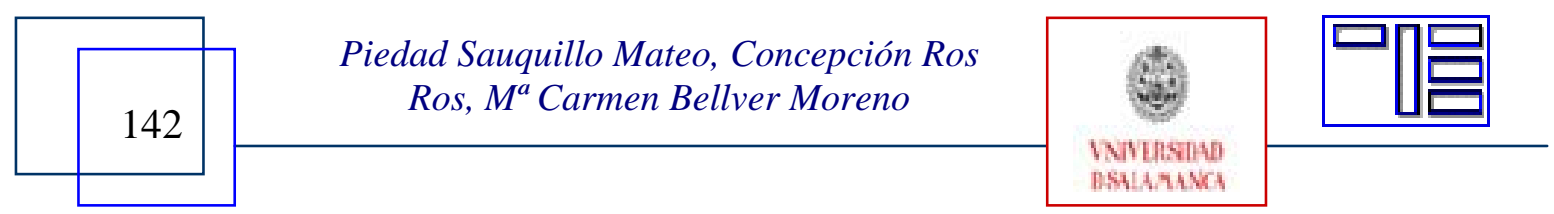


En esta categoría observamos que en los videojuegos analizados existe una mayoría de protagonistas masculinos (70\%) que femeninos (30\%). No obstante hay que mencionar que en la primera variable (protagonistas masculinos) se han incluido casos en que se dan protagonistas de los dos sexos, pero siempre la proporción es mayor en el género masculino. Además, en el caso en que la protagonista es una mujer, esta figura adquiere connotaciones claramente masculinas, es decir los roles que desempeñan están dentro de lo que se denomina "cultura macho", (caracterizada por valores como la competitividad y el triunfo,, la violencia, el racismo, las impulsividad, la irresponsabilidad), en la que la figura femenina se masculiniza y se exaltan los valores y roles tradicionalmente masculinos (sexismo implícito). Como señala Díez (2004: 113114), en su estudio un 70,26\% (frente al 29'74\%) de los que respondieron al cuestionario consideraban que las misiones que desempeñaban los hombres y las mujeres en los videojuegos eran iguales, esto supone que tanto hombres como mujeres no perciben la desigualdad, ya que no son conscientes del contexto desigual en el que están inmersos y han sido socializados mujeres y hombres, sin olvidar que estamos hablando de una población que se ha educado en una época donde la igualdad debiera ser la obligación y la norma ( nuestra Constitución Española, fue aprobada en 1978).

Por último, no se ha encontrado en ningún videojuego la proporción equitativa entre los dos géneros.

Categoría 2: Relación que se establece entre los roles hombre/mujer en los videojuegos: Tabla ${ }^{\circ} 3$

\begin{tabular}{|l|c|c|c|}
\cline { 2 - 4 } \multicolumn{1}{c|}{} & DOMINACIÓN & IGUALDAD & $\begin{array}{l}\text { NO ES } \\
\text { RELEVANTE }\end{array}$ \\
\hline $\begin{array}{l}\text { RELACIÓN ROLES } \\
\text { HOMBRE/MUJER }\end{array}$ & $90 \%$ & $10 \%$ & - \\
\hline
\end{tabular}

La relación entre hombre y mujer, es en el 90\% de los videojuegos analizados de dominancia, del hombre hacia la mujer. Según Díez (2004:112-113), las relaciones entre las mujeres y los hombres la percepción es diferente según sexos, pues los hombres no percibían las relaciones de dominio, sin embargo las mujeres cada vez lo percibían de una forma más clara. Diversos estudios realizados hasta el momento, Provenzo (1991), Estalló (1995), Etxeberría (1999), Urbina y otros (2002), Conocedoras (2003), Díez (2004), confirman que a pesar del tiempo transcurrido, el cambio de sensibilidad social relativo al tema no parece haber producido grandes modificaciones en el tratamiento de la figura femenina, pues la mujer aparece más en los videojuegos, la figura femenina sigue con rasgos pasivos (princesas buenas) o de sumisión, o como mujeres malas y eróticas (sexy). Los datos del estudio de Díez (2004:350-351) confirman el predominio de un estilo de interacción pasivo (77\%) (modelo masoquista, como en Resident Evil, Super Mario y cuando representan un papel activo es una copia del modelo masculino (competitividad, agresividad...), siendo una réplica del perfil masculino del

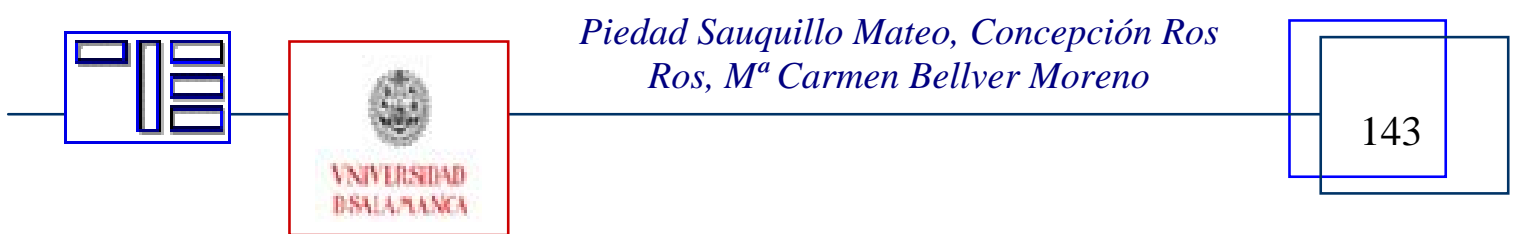


protagonista, es decir lo único que cambia son los atributos sexuales de la protagonista (modelo sádico, que podemos encontrar en videojuegos como Mortal Kombat o Lara Croft).

Hemos considerado que en el caso del videojuego "Pokemon" existe un trato de igualdad al poder ser entrenador de las mascotas (pokemons) tanto un hombre como una mujer.

Categoría 3: Tratamiento de la figura de la mujer en el videojuego

\begin{tabular}{|l|c|c|c|}
\multicolumn{1}{c|}{} & \multicolumn{1}{c|}{${\operatorname{Tabla~}{ }^{\circ} 4}$} \\
\cline { 2 - 4 } \multicolumn{1}{c|}{} & ERÓTICA/SEXY & PASIVA & AGRESIVA \\
\hline $\begin{array}{l}\text { TRATAMIENTO DE LA FIGURA DE LA } \\
\text { MUJER EN EL VIDEOJUEGO }\end{array}$ & $30 \%$ & $60 \%$ & $10 \%$ \\
\hline
\end{tabular}

En esta categoría podemos analizar el abanico de roles y la imagen asociada a ellos, que tiene la mujer en los videojuegos analizados: un 30\% presenta a la mujer como un objeto erótico y sexual dentro de los cánones de la cultura machista (cuerpo escultural, insinuantes, ciberheroínas). Un 10\% la presenta a la mujer como agresiva (en el papel de luchadoras, figuras andróginas) asumiendo patrones de comportamiento masculinizados. La mayoría (un 60\%) presenta un rol de "mujer pasiva" dependiente del rol masculino, asumiendo papeles de mujeres desvalidas que han de ser cuidadas o rescatadas por las figuras masculinas imágenes adolescentes, inocentes y con necesidad de protección), o como objetos sexuales (prostitutas). Es de destacar el rol que en el videojuego GTA ofrece de las mujeres: son prostitutas a las que se puede utilizar como objetos sexuales y luego matar sin ningún pudor.

Categoría 4: Valores/Disvalores socioculturales que se trasmiten a través del contexto/acción en que se desarrolla el videojuego

\begin{tabular}{|l|c|c|}
\multicolumn{2}{c}{ Tabla $^{\circ} 5$} \\
\cline { 3 - 4 } \multicolumn{1}{c|}{} & $\begin{array}{l}\text { VALORES } \\
\text { SOCIALES } \\
\text { ADECUADOS }\end{array}$ & $\begin{array}{l}\text { VALORES } \\
\text { BÉLICOS }\end{array}$ \\
\hline $\begin{array}{l}\text { VALORES SOCIOCULTURALES QUE SE } \\
\text { TRASMITEN A TRAVÉS DEL VIDEOJUEGO }\end{array}$ & $10 \%$ & $90 \%$ \\
\hline
\end{tabular}

En la gran mayoría de los videojuegos analizados un $90 \%$ de los valores que se trasmiten por el contexto donde se desarrolla la acción del juego son de carácter bélico (guerras, violencia, delincuencias, muertes, etc...). El único videojuego de los analizados que ofrece un modelo social alternativo y adecuado es el juego de "The Sims” donde el jugador alcanza más puntos en función del logro de valores sociales occidentales: tener una familia, una casa, un trabajo, etc... El jugador pierde puntos en la medida que establece comportamientos alejados de la "norma social”:por ejemplo ser

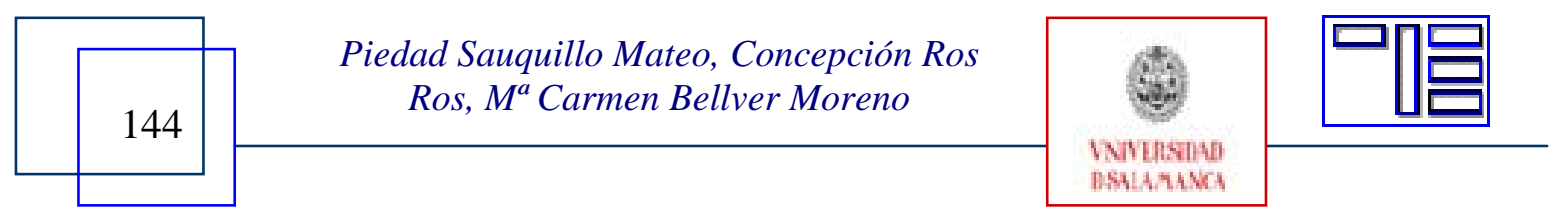


madre soltera, lesbiana, etc... Es un juego que ayuda a replantearse la organización social del mundo más desarrollado.

Categoría 5: Análisis de los valores que transmite el rol femenino en los videojuegos $\underline{\operatorname{Tabla~}^{\circ} 6}$

\begin{tabular}{|l|c|l|c|}
\cline { 2 - 4 } \multicolumn{1}{c|}{} & AGRESIVIDAD & $\begin{array}{l}\text { MATERNAL: AMAR, } \\
\text { CUIDAR, }\end{array}$ & $\begin{array}{l}\text { MASCULINOS: } \\
\text { COMPETICIÓN,.. }\end{array}$ \\
\hline $\begin{array}{l}\text { VALORES QUE TRASMITE } \\
\text { EL ROL FEMENINO }\end{array}$ & $40 \%$ & $30 \%$ & $30 \%$ \\
\hline
\end{tabular}

De acuerdo a la categoría anterior que analizaba el rol de la mujer, los valores/disvalores femeninos que se trasmiten a través de las figuras femeninas en los videojuegos analizados son en su mayoría agresivos (40\%) que unido al porcentaje de valores “masculinos" como competición, etc., suman un total del $70 \%$ de los valores que se trasmiten a través de este tipo de juegos. Otro 30\% trasmite valores maternales (de ayuda, de cuidado, necesidad de ser rescatadas y protegidas por el héroe masculino, etc..). Entendemos pues que tal como señalaba Díez (2004:243) sigue siendo obvio la total ausencia de estilos asertivos tan necesarios como referentes en nuestra cultura y sociedad actual.

\section{5.- DISCUSIÓN}

En síntesis, los videojuegos con que conviven a diario los menores y adolescentes ofrecen, en ocasiones, contenidos que, desde nuestro punto de vista, requieren de una buena intervención pedagógica para su entendimiento y reflexión. Sin embargo, para el desarrollo de esta ardua pero necesaria tarea se hace indispensable la co-implicación de las distintas agencias y contextos implicados en la educación de dicha población. Como educadores debemos considerar que el camino hacia la igualdad efectiva entre mujeres y hombres es largo y que aún queda mucho por recorrer.

En este contexto, cabe destacar el insustituible papel de la familia como agencia mediadora en el proceso, no sólo por los mensajes que en su seno se transmite a los niños sino, fundamentalmente, por las barreras y límites que establece. Hemos de concienciar a las familias del papel insustituible que realizan como filtro ante las influencias del medio a que se encuentran expuestos sus hijos/as. Las familias tienen un papel fundamental en la elección de los juegos (pues son quienes los compran), deben conocer el contenido de los mismos para elegir el más adecuado según las edades, siendo preferibles juegos que permitan la participación de más de un jugador o jugadora y ser así copartícipes en esta actividad. Así pues, corroboramos con nuestro trabajo la necesidad de formación e implicación familiar.

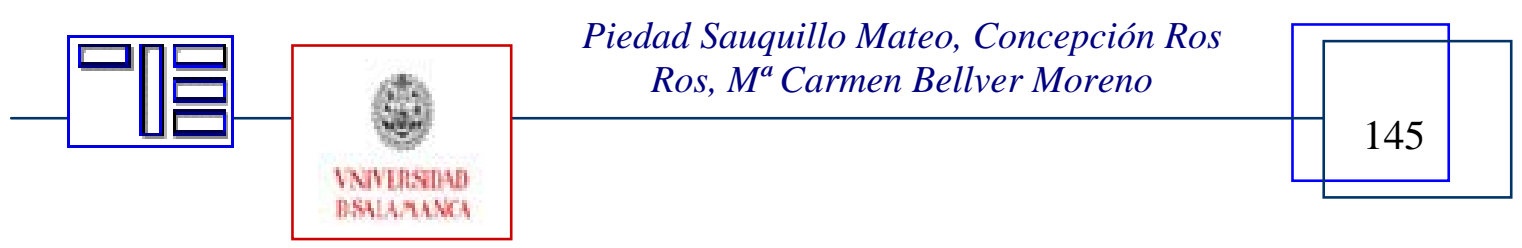




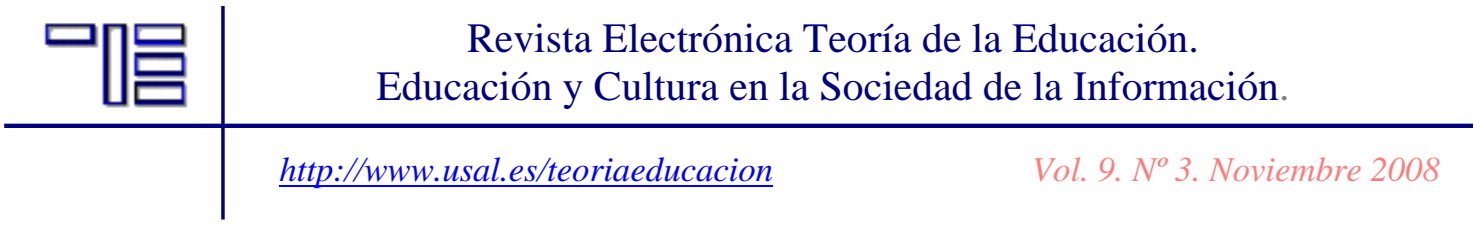

Teniendo en cuenta que los videojuegos son actualmente una de las actividades de ocio más comunes entre los europeos, que abarca todas las edades, sexos y nacionalidades (según datos de "Interactive Software Federation of Europe"), y teniendo en cuenta el gran potencial inculcador que puede derivarse de los contenidos ofrecidos, consideramos de gran importancia abordar el tema de los modelos de género ofrecidos, pues trascurridos más de 15 años desde el estudio de Provenzo (1991), el cambio de sensibilidad relativo al tema aún no ha producido muchas modificaciones en el. tratamiento de la figura femenina. Se siguen transmitiendo gran cantidad de disvalores respecto a la figura y el rol femenino.

Los videojuegos son, como venimos planteando, una de las actividades que ocupa el tiempo de ocio de nuestros niños, niñas y adolescentes. Debemos tener en cuenta la responsabilidad de los educadores (escuela y familia) de ofrecer herramientas educativas, instrumentos de análisis crítico que permitan una reflexión de los contenidos ofrecidos por los videojuegos, pues éstos son una fuente de asentamiento de valores y potenciación de actitudes y formas de resolver conflictos. No cabe duda de que el ámbito escolar es un espacio desde el que tenemos que intervenir para conseguir una sociedad sin discriminaciones, y avanzar en la igualdad de género.

Sin duda, con nuestro trabajo no hemos pretendido agotar todas las posibilidades de investigación respecto a la realidad estudiada, antes bien al contrario. Así, una de las propuestas para futuras investigaciones consiste en analizar si tanto los menores y adolescentes como sus familias están formados para el análisis crítico de los videojuegos y si, por ende, no se apropian de los contenidos que a través de este medio se les transmite sino que son capaces de cuestionarlos y discernir si están de acuerdo o no con ellos y si contribuyen a su proceso de formación o lo dificultan. Si bien es cierto que esto ha sido estudiado en relación con el contexto escolar no se ha trabajado respecto a la familia y, desde nuestra perspectiva, la implicación tanto de la familia como de la escuela son necesarias si queremos contribuir a la educación para la igualdad de quienes serán nuestro futuro.

En este sentido, a continuación tratamos de ofrecer una serie de pautas y orientaciones pedagógicas que pretenden contribuir a la mejora de la realidad estudiada.

Los padres deben buscar información práctica sobre las características de los videojuegos y los sistemas de etiquetado por edades que incluyen estos productos, siendo necesario informarse y responsabilizarse de la compra a la hora de adquirirlos.

Sin embargo, es más importante si cabe que los padres reciban una formación adecuada para poder analizar críticamente los contenidos que los videojuegos ofrecen, prestando especial atención a aquellos que favorecen actitudes discriminatorias (por razón de género, cultura, lengua, etc.). De este modo podrán contribuir a la formación de un

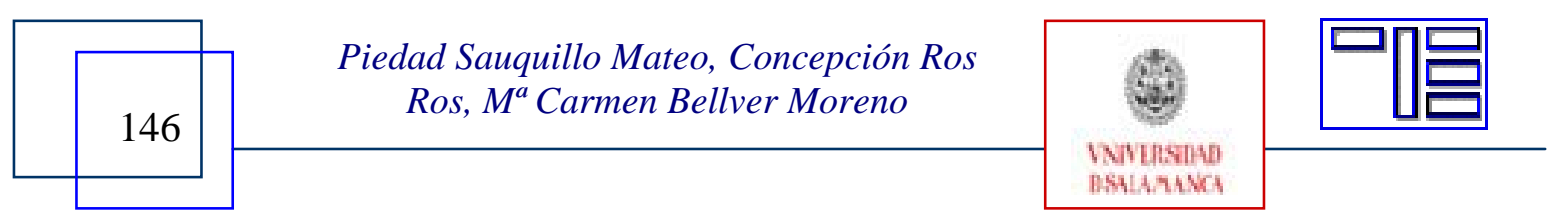


juicio crítico razonado en sus hijos mientras hablan sobre aquello a lo que han jugado, comentan qué les ha gustado más o menos e incluso mientras juegan.

Por otra parte, los tiempos que se dediquen al uso y disfrute de los videojuegos deben ser limitados y pactados con sus hijos, previamente, atendiendo a las preferencias e intereses de los más pequeños (siempre que esto no resulte perjudicial para su proceso de formación como persona). Sin duda, a edades más tempranas será necesaria una mayor y pautas claras.

En definitiva, los padres deben ser conscientes de la necesidad de reservar y compartir tiempos de ocio con sus hijos que les permita conocer los contenidos que transmiten los videojuegos y dialogar-reflexionar sobre lo que les ofrece, de modo que puedan participar de su educación como mediadores, tratando de orientarles, actuando como guía en su proceso de crecimiento como persona.

\section{6.- BIBLIOGRAFÍA}

BARTHELMES, J. (1990) ¿Por qué miras? Relación de los media y las familias, Infancia y Sociedad, 3, 50 - 63.

CABERO, J. y LOSCERTALES, F. (1995): La imagen del profesorado y la enseñanza en los medios de comunicación de masas, Revista de Educación, 306, 87- 125.

CONOCEDORAS (2003) Una cara bonita no es suficiente. http://mujeres chile.cl/conocedoras/artículo.php?articulo=279\&area=cultura $(14 / 10 / 03)$

DE BOFARULL, I. (2005) Ocio y tiempo libre: un reto para la familia. Navarra, Eunsa.

DEFLEUR, M. L. (1964) Occupational roles as portrayed on televisión, Public Opinion Quarterly, 28, 57-74.

DÍEZ , E.J. (Dir) (2004) La diferencia sexual en el análisis de los videojuegos. Madrid: CIDE/Instituto de la Mujer..

ESTALLÓ, J.A. (1995) Los videojuegos. Juicios y prejuicios. Barcelona. Planeta

ELZO, J y Otros (1994) Jóvenes españoles 94. Madrid, S.M.

ETXEBERRÍA, F. (1999) Videojuegos y educación. En Etxeberría, F (coord.): La Educación en Telépolis. Donostia: Ibaet

FERRÉS, J. (1998) La televisión en tiempos de cambio, Comunicación y Pedagogía, $151,142-146$.

GARBARINO, J., DUBROW, N., KOSTELNY, K. y PARDO, C. (1992) Children in Danger: Coping with the Consequences of Community Violence. San Francisco, Jossey-Bass.

GARGALLO, B (2008) Género y nuevas tecnologías., en AZNAR, P.; CÁNOVAS, P. (2008) Educación, género y Políticas de igualdad. Valencia. Universidat de València

GÓMEZ DEL CASTILLO, M. T. (2001): Análisis de valores en el software educativo multimedia. Tesis doctoral. Universidad de Sevilla.

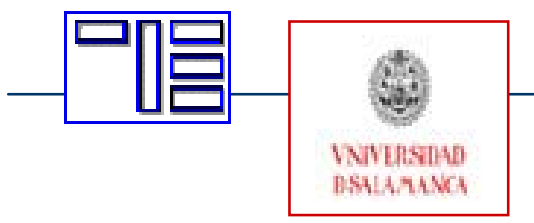

Piedad Sauquillo Mateo, Concepción Ros Ros, $M^{a}$ Carmen Bellver Moreno 
GROS, B. (1998). Jugando con videojuegos. Educación y entretenimiento. Bilbao. Desclée de Brouwer.

HARTLEY, J. (2000) Los usos de la televisión. Barcelona, Paidós.

HALLORAN, J. (1974) Los efectos de la televisión. Madrid, Editorial Nacional.

II Foro Galego sobre Mulleres e medios de comunicación (2000)

IV Conferencia Mundial sobre la Mujer (1995)

V Conferencia Mundial sobre la Mujer (2005)

LEVINE, M. (1997) La violencia en los medios de comunicación: cómo afecta al desarrollo de los niños y adolescentes. Bogotá, Norma.

LEY ORGÁNICA 3/2007, de 22 de marzo, para la igualdad efectiva de mujeres y hombres. (BOE n. 71 de 23/3/2007)

MARQUÉS, P. (2000): Los videojuegos. <http://dewey.uab.es/pmarques/ videojue.htm>.

MEDIAN, C. (2000) La televisión y su influencia en los niños, en http://www.intec.edu.do/-cdp/docs/Television.htm

MERTON, R. K. (1964) Mass persuasion. New York, Harper.

MARTÍN SERRANO, M. (1990) La participación de los medios audiovisuales en la construcción de la visión del mundo de los niños, Infancia y sociedad, 3, 5 18.

NIELSEN GAMES (2008) Informe Jugadores de videojuegos en Europa 2008. Interactive Software Federation of Europe, www.isfe.eu

PÉREZ ALONSO - GETA, P. M ${ }^{a}$ (1994) Tiempo de ocio y televisión en la infancia y la adolescencia, en AA.VV. Televisión. Niños y jóvenes. Valencia, RTVV.

PÉREZ ALONSO-GETA, P. M $\mathrm{M}^{\mathrm{a}}$. (2005) La reducción de la infancia, Le Monde Diplomatique, 111.

PÉREZ TORNERO, J. M. (1994) El desafío educativo de la televisión. Para comprender y usar el medio. Barcelona, Paidós.

POSTMAN, N. (1982) The disappearance of childhood. New Cork, Delacorte Press.

POSTMAN, N. (1990) La desaparició de la infantesa, Barcelona, Eumo.

PROVENZO, E.F. (1991) Video Kids: making sense of Nintendo. Crambridge: Harvard University Press.

RODRÍGUEZ, E. (2002): Jóvenes y videojuegos. Madrid, MEC.

ROSENGREN, K. E. (1992) The structural invariance of change: comparative studies of media use, en BLUMLER et al. (Eds.) Comparatively Speaking: communication and culture across space and time. Newbury Park, CA, Sage, 140-178).

SANDER, E. (1990) Los medios de comunicación en la vida cotidiana de la familia. Relación generacional y cultura juvenil, Infancia y sociedad, 3, 19 - 29.

SARTORI, G. (1998) Homo videns. La sociedad teledirigida. Madrid, Taurus.

TUCHMAN, G. (1988) Mass Media Institutions, en SMELSER (comp.) Handbook of Sociology. Newbury Park, Sage, 601-626.

TUCHMAN, G., DANIELS, A. K. y BENET, J. (1978) Hearth and Home: images of women in mass media. Nueva York, Oxford University Press.

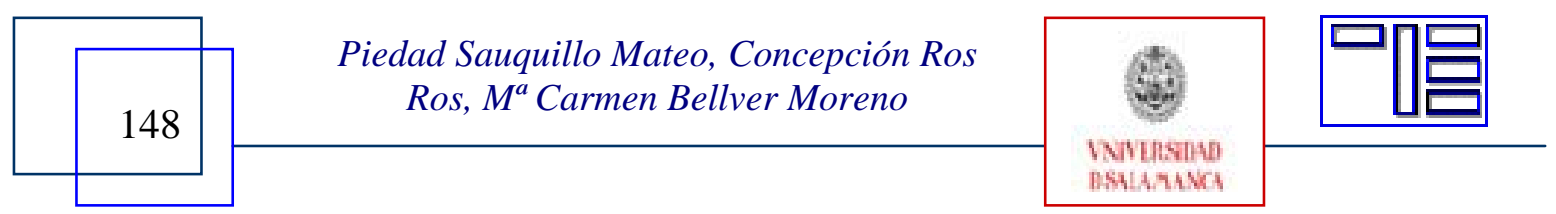


TUYA, M (2000) Mujeres y tecnología, atracción fatal. http://www.baquia.com/com/legacy/13764.html

URBINA, S.,RIERA, B., ORTEGO, J.L. y GISBERT, S. (2002) El rol de la figura femenina en los videojuegos. Edutec. Revista Electrónica de Tecnología Educativa, 15

VAN EVRA, J. (1990) Television and child development. Hillsdale, NJ, Llawrence Erlbaum.

VILCHES, L. (1999) La televisión: los efectos del bien y del mal. Barcelona, Paidós Ibérica.

Para citar la presente editorial puede utilizar la siguiente referencia:

SAHUQUILLO MATEO, Piedad; ROS ROS, Concepción; BELLVER MORENO, M ${ }^{\mathrm{a}}$ Carmen (2008). El rol de género en los videojuegos. En SÁNCHEZ i PERIS, Francesc J. (Coord.) Videojuegos: una herramienta educativa del "homo digitalis" [monográfico en línea]. Revista Electrónica Teoría de la Educación: Educación y Cultura en la Sociedad de la Información. Vol. 9, $\mathrm{n}^{\circ}$ 3. Universidad de Salamanca [Fecha de consulta: $\mathrm{dd} / \mathrm{mm} / \mathrm{aaaa}]$.

http://www.usal.es/ teoriaeducacion/rev_numero_09_03/n9_03_sauquillo_ros_bellver.pdf ISSN: 1138-9737

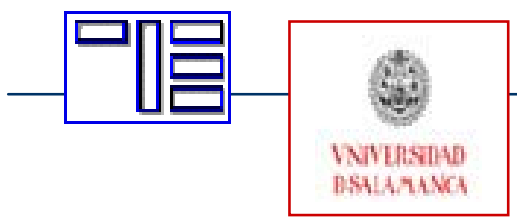

Piedad Sauquillo Mateo, Concepción Ros Ros, $M^{a}$ Carmen Bellver Moreno 